\title{
EFEKTIVITAS KONSELING KELOMPOK MENGGUNAKAN PENDEKATAN RATIONAL EMOTIVE BEHAVIOR THERAPY (REBT) UNTUK MENGURANGI KECEMASAN PESERTA DIDIK SMP IT MASJID SYUHADAK YOGYAKARTA
}

\author{
Citra Sari $^{(1)}$, Makin ${ }^{(2)}$ \\ Program Studi Bimbingan dan Konseling \\ Fakultas Keguruan dan Ilmu Pendidikan \\ Univeristas PGRI Yogyakarta \\ E-mail: makinsh11@gmail.com
}

\begin{abstract}
Abstrak
Penelitian bertujuan menemukan bukti empiris keefektifan konseling kelompok dengan pendekatan Rational Emotive Behavior Therapy (REBT) untuk menurunkan kecemasan peserta didik Sekolah Menengah Pertama Islam Terpadu (SMP-IT) Masjid Syuhadak Yogyakarta. Prosedur penelitian mengacu pada tahapan penelitian eksperimen jenis OneGroup Pretest-Postest Design. Subyek eksperimen berjumlah 7 peserta didik yang diidentifikasi memiliki kecemasan tingkat tinggi berdasarkan hasil asesmen menggunakan instrumen angket. Eksperimen dilakukan dengan memberikan konseling kelompok menggunakan pendekatan Rational Emotive Behavior Therapy kepada subyek eksperimen. Data hasil eksperimen dianalisis dengan T-test. Hasil analisis data menunjukkan nilai t: 8,908 dengan p: $0,00<0,05$ yang berarti konseling kelompok menggunakan pendekatan Rational Emotive Behavior Therapy (REBT) terbukti efektif menurunkan tingkat kecemasan peserta didik Sekolah Menengah Pertama Islam Terpadu (SMP-IT) Masjid Syuhadak Yogyakarta.
\end{abstract}

Kata kunci: konseling kelompok, REBT, kecemasan

\begin{abstract}
The study aims to find empirical evidence on the effectiveness of group counseling with the approach of Rational Emotive Behavior Therapy (REBT) to reduce the anxiety of students of the Integrated Islamic Junior High School (SMP-IT) Masjid Syuhadak Yogyakarta. The research procedure refers to the stages of the experimental research type One-Group Pretest-Postest Design. The experimental subjects were 7 students who were identified as having high level of anxiety based on the assessment results using a questionnaire instrument. The experiment was conducted by providing group counseling using the Rational Emotive Behavior Therapy approach to the experimental subjects. The experimental data were analyzed by T-test. The results of data analysis showed a value of t: 8.908 with p: $0.00<0.05$ which means that group counseling using the Rational Emotive Behavior Therapy (REBT) approach proved effective in reducing the anxiety level of Syuhadak Mosque Junior High School (SMP-IT) students. Yogyakarta.
\end{abstract}

Keywords: group counseling, REBT, anxiety

Info Artikel

Diterima Oktober 2018, disetujui November 2018, diterbitkan Desember 2018

Dipublikasikan Oleh: Program Studi Bimbingan dan Konseling Fakultas Keguruan dan Ilmu Pendidikan Universitas PGRI Yogyakarta 


\section{PENDAHULUAN}

Kecemasan yang menandai adanya kondisi kejiwaan yang penuh dengan kekhawatiran dan ketakutan terhadap apa yang mungkin terjadi, bisa terjadi pada siapapun, kapanpun dan dimanapun. Seseorang yang mengalami kecemasan akan menunjukkan gejala berkeringat, tangan dingin, lemas, menggigil, mual dan detak jantung yang semakin cepat serta gejala lain yang serupa. Seperti yang dialami oleh beberapa peserta didik Sekolah Menengah Pertama Islam Terpadu (SMP-IT) Masjid Syuhadak Yogyakarta, saat dipilih untuk berbicara di depan kelas tibatiba menjadi gagap, tidak berbicara sama sekali atau bahkan menolak untuk maju.

Dalam konteks tugas Guru Bimbingan dan Konseling, kecemasan yang dialami peserta didik dapat menghambat pencapaian perkembangan secara optimal yang menjadi tujuan sejumlah layanan bimbingan dan konseling di sekolah. Upaya bantuan untuk mengatasi masalah kecemasan peserta didik dapat dilakukan melalui layanan konseling kelompok dengan pendekatan Rational Emotive Behavior Therapy (REBT).

Tohirin (2013: 172) menjelaskan konseling kelompok sebagai upaya pembimbing atau konselor membantu memecahkan masalah-masalah pribadi yang dialami oleh masing-masing peserta didik melalui kegiatan kelompok agar tercapai perkembangan yang optimal. Layanan konseling kelompok akan membuat peserta didik saling bertukar pikiran, sehingga peserta didik secara tidak langsung melatih diri berbicara di depan umum. Dengan menerapkan pendekatan REBT maka dinamika dalam proses konseling kelompok terfokus pada upaya bersama mengubah cara berpikir tidak rasional menjadi rasional. Sebagaimana dijelaskan oleh Kurnanto (2013: 67) bahwa pendekatan Rational Emotive Behavior Therapy menekankan kebersamaan dan reaksi antara berfikir dan akal sehat (rational), berperasaan (emoting), dan berperilaku (acting). Pendekatan ini merupakan aliran psikoterapi yang berlandaskan pandangan bahwa manusia terlahir dengan potensi untuk berfikir rasional dan jujur maupun untuk berfikir irasional atau jahat. George \& Cristiani (dalam Gantina, 2016: 202203) menjelaskan pendekatan Rational Emotive Behavior Therapy (REBT) berasumsi bahwa individu memiliki karakteristik: 1) individu memiliki potensi yang unik untuk berpikir rasional dan irasional. Pikiran irasional berasal dari proses belajar yang irasional yang didapat dari orangtua dan budayanya; 2) manusia adalah makhluk verbal dan berpikir melalui simbol dan bahasa. Dengan demikian, gangguan emosi yang dialami individu disebabkan oleh verbalisasi ide dan pemikiran irasional; 3) gangguan emosional yang disebabkan oleh verbalisasi diri (self 
verbalising) yang terus menerus dan persepsi serta sikap terhadap kejadian merupakan akar permasalahan, bukan karena kejadian itu sendiri; 4) individu memiliki potensi untuk mengubah arah hidup personal dan sosialnya; 5) pikiran dan perasaan yang negatif dan merusak diri dapat diserang dengan mengorganisasikan kembali persepsi dan pemikiran, sehingga menjadi logis dan rasional. Dalam hal gangguan emosi yang disebabkan oleh verbalisasi ide dan pemikiran irasional, Ellis (dalam Gantina, 2016: 208-209) berpendapat bahwa yang menjadi sumber terjadinya masalahmasalah emosional itu adalah evaluative belief yang disebut dalam Rational Emotive Behavior Therapy sebagai irrational belief (berpikir irasional). Ada empat kategori irrational belief : 1) Demands yang berarti adanya tuntutan atau ekspektasi yang tidak realistis dan absolut terhadap kejadian atau individu yang dapat dikenali dengan kata-kata seperti, harus, sebaiknya, dan lebih baik; 2) Awfulising yang berarti cara melebih-lebihkan konsekuensi negatif dari suatu situasi sampai pada level yang ekstrim sehingga kejadian yang tidak menguntungkan menjadi kejadian yang sangat menyakitkan; 3) Low Frustation Tolerance (LTF), yaitu kelanjutan dari tuntutan untuk selalu berada dalam kondisi nyaman dan merefleksikan ketidaktoleransian terhadap ketidaknyamanan; 4) Global evaluations of human wort, yaitu menilai keberhargaan diri sendiri dan orang lain. Hal ini bermakna bahwa individu dapat diberi peringkat yang berimplikasi pada asumsi beberapa orang lebih buruk atau tidak berharga dari yang lain. Selanjutnya, Ellis membagi pikiran individu dalam tiga tingkatan, yaitu: dingin (cool), hangat (warm), dan panas (hot) yang mengilustrasikan bagaimana emosi terintegrasi dalam pikiran. Pikiran dingin (cool) adalah pikiran yang bersifat deskriptif dan mengandung sedikit emosi. Hangat (warm) adalah pikiran yang mengarah pada suatu prefensi atau keyakinan rasional, pikiran ini mengandung unsur evaluasi yang menpengaruhi pembentukan perasaan. Panas (hot) adalah pikiran yang mengandung unsur evaluasi yang tinggi dan penuh dengan perasaan. Lebih lanjut Ellis menegaskan bahwa irational belief menjadi masalah bagi individu karena: 1) menghambat individu dalam mencapai tujuantujuan, menciptakan emosi yang ekstrim yang mengakibatkan stres dan menghambat mobilitas dan megarahkan pada tingkah laku yang menyakiti diri sendiri; 2) menyalahkan kenyataan (salah menginterpretasikan kejadian yang terjadi atau tidak didukung oleh bukti yang kuat); 3) mengandung cara yang tidak logis dalam mengevaluasi diri, orang lain dan lingkungan sekitar.

Implikasi praktis penerapan pendekatan Rational Emotive Behavior Therapy (REBT) dalam pelaksanaan konseling kelompok yang ditujukan untuk mengatasi masalah 
kecemasan peserta didik terutama menyangkut peran pembimbing/konselor pada upaya membangkitkan kesadaran peserta didik untuk mengubah cara berpikir tidak rasional menjadi rasional sehingga kecemasan yang bersumber dari cara berpikir tidak rasional akan menurun atau dapat dihalangkan .

\section{METODE PENELITIAN}

Penelitian dilaksanakan di Sekolah Menengah Pertama Islam Terpadu (SMP-IT) Masjid Syuhadak Yogyakarta. Subyek penelitian berjumlah 7 peserta didik sebagai sampel purposive yang diidentifikasi memiliki tingkat kecemasan tinggi berdasarkan hasil asesmen menggunakan instrumen angket yang disusun berdasarkan indikator variabel kecemasan. Prosedur penelitian mengacu pada tahap-tahap pelaksanaan penelitian eksperimen dengan One-Group Pretest-Postest Design, meliputi tahap pengumpulan data awal (pretest), tahap pemberian perlakuan (treatment), tahap pengumpulan data ahir (posttest), tahap analisis data, dan tahap penyimpulan hasil. Pengumpulan data awal dan ahir tentang kecemasan subyek penelitian menggunakan metode angket dengan instrumen berupa angket yang telah diuji dan memenuhi standar validitas dan reliabelitas yang dipersyaratkan. Pemberian perlakuan dilaksanakan dengan memberikan layanan konseling kelompok menggunakan pendekatan Rational Emotive Behavior Therapy (REBT) kepada subyek penelitian/ eksperimen. Data hasil penelitian dianalisis secara statistik menggunakan uji-t (T-test).

\section{HASIL PENELITIAN DAN PEMBAHASAN}

Jenis penelitian eksperimen berintikan pada pemberian perlakuan (treatment) kepada subyek eksperimen. Dalam penelitian pemberian perlakuan dilakukan oleh peneliti dibantu mahasiswa program studi Bimbingan dan konseling yang sedang menyelesaikan tugas ahir. Pemberian perlakuan konseling kelompok menggunakan pendekatan Rational Emotive Behavior Therapy (REBT) dilaksanakan mengacu pada rancangan sebagai berikut.

1. Identifikasi masalah konseli:

- Mengklarifikasi hasil pretest apakah sesuai dengan keadaan konseli yang sesungguhnya atau tidak

- Mengetahui seberapa sering konseli mengalami kecemasan

- Menemukan inti masalah yang mendasari konseli mengalami kecemasan

2. Goal Setting

- Menentukan tujuan konseling

- Memberikan pandangan mengenai tujuan yang dicapai

- Meyakinkan konseli bahwa peneliti ingin membantu konseli mencapai tujuan konseling

3. Implementasi Teknik I

- Menjelaskan pengertian, tahap pelaksanaan pendekatan 


\section{REBT}

- Menentukan tujuan yang akan dicapai $(\mathrm{G})$

- Menentukan kejadian atau peristiwa yang dialami konseli (A)

- Melihat keyakinan yang dimiliki konseli (B)

- Melihat kosekuensi yang muncul $(\mathrm{C})$

4. Implementasi Teknik II

- Menentang keyakinankeyakinan yang irasional (D)

- Mengembangkan pikiran rasional
5. Evaluasi dan Pengakhiran

- Mengevaliasi langkah lanjutan yang akan dilakukan konseli setelah mendapatkan treatment

- Mengeksplorasi kemungkinan kebutuhan konseling tambahan

- Membantu konseli berkomitmen mengaplikasikan apa yang telah dipelajari

Berikut ini dipaparkan hasil penelitian berdasarkan hasil analisis data Pre-test dan Post-test serta analisis uji-t menggunakan aplikasi program SPSS (statistical Package for Sosial Sciense) versi 16.0 for window dapat dipaparkan rangkuman hasil penelitian sebagai berikut

Tabel 1.

Mean Pre-test dan Post-test

Paired Samples Statistics

\begin{tabular}{|ll|r|r|r|r|}
\hline & & Mean & $\mathrm{N}$ & Std. Deviation & \multicolumn{1}{c|}{ Std. Error Mean } \\
\hline Pair 1 & posttest & 74.5714 & 7 & 7.52456 & 2.84402 \\
& Pretest & 102.8571 & 7 & 9.99047 & 3.77604 \\
\hline
\end{tabular}

Pada tabel di atas menunjukkan adanya perbedaan rata- rata skor kecemasan antara hasil pre-test dan post-test. Rata-rata pre-test sebesar 102,8571 sedangkan rata-rata post-test setelah sebesar 74,5714. Dengan demikian terdapat selisih skor ratarata kecemasan peserta didik antara sebelum dan sesudah mendapatkan layanan konseling kelompok sebesar 28,2857 .

Tabel 2.

Hasil Uji Paired T-tes

Paired Samples Test

\begin{tabular}{|c|c|c|c|c|c|c|c|c|}
\hline & \multicolumn{5}{|c|}{ Paired Differences } & \multirow[b]{3}{*}{$\mathrm{t}$} & \multirow[b]{3}{*}{$\mathrm{df}$} & \multirow{3}{*}{$\begin{array}{l}\text { Sig. } \\
(2- \\
\text { tailed) }\end{array}$} \\
\hline & \multirow[b]{2}{*}{ Mean } & \multirow{2}{*}{$\begin{array}{c}\text { Std. } \\
\text { Deviatio } \\
\mathrm{n}\end{array}$} & \multirow{2}{*}{$\begin{array}{l}\text { Std. } \\
\text { Error } \\
\text { Mean }\end{array}$} & \multicolumn{2}{|c|}{$\begin{array}{l}95 \% \text { Confidence } \\
\text { Interval of the } \\
\text { Difference }\end{array}$} & & & \\
\hline & & & & Lower & Upper & & & \\
\hline $\begin{array}{c}\text { Pair } 1 \text { posttest - } \\
\text { Pretest }\end{array}$ & -28.28571 & 8.40068 & 3.17516 & -36.05505 & -20.51638 & -8.908 & 6 & .000 \\
\hline
\end{tabular}


Berdasarkan hasil analisis data diperoleh nilai $\mathrm{t}=8,908$ dengan $\mathrm{p}=$ $0,000<0,05$ yang berarti ada perbedaan yang signifikan tingkat kecemasan peserta didik antara sebelum dan sesudah mendapatkan layanan konseling kelompok menggunakan pendekatan Rational Emotive Behavior Therapy (REBT).

Kesimpulan hasil analisis statistk yang dipaparkan di atas membuktikan hipotesis penelitian yang menyatakan bahwa pemberian layanan konseling kelompok menggunakan pendekatan Rational Emotive Behavior Therapy (REBT) dapat menurunkan tingkat kecemasan peserta didik Sekolah Menengah Pertama Islam Terpadu (SMP-IT) Masjid Syuhadak Yogyakarta.

Penurunan tingkat kecemasan peserta didik dapat dijelaskan berdasarkan pengamatan peneliti selama pemberian layanan konseling kelompok bahwa semua peserta didik berpartisipasi cukup aktif baik bertanya maupun merespon pembicaraan anggota kelompok. Hasil refleksi setelah berahirnya proses konseling semua peserta didik mengikuti serangkaian pertemuan dengan baik sehingga masing-masing peserta didik mampu memahami masalah yang dialami dan mengembangkan mode berpikir yang lebih rasional serta memiliki komitmen untuk mencapai tujuan yang dinginkan. Penurunan tingkat kecemasan peserta didik sebagian dapat dilihat dalam setiap pertemuan konseling kelompok yang pada awalnya kurang terbuka, takut menjawab pertanyaan bahkan hanya menyimak, menjadi lebih terbuka, berani menjawab pertanyaan yang diajukan, berdiskusi dan memberikan tanggapan ketika anggota kelompok yang lain mengajukan pertanyaan. Secara keseluruhan anggota kelompok mengaku mendapatkan pengalaman belajar yang sangat berharga yaitu dapat memahami apa yang mereka pikirkan selama ini membuat mereka menjadi tidak maksimal. Pada ahirnya berkomitmen terhadap diri sendiri untuk merubah cara berpikir agar mereka menjadi lebih aktif dan produktif. Kesimpulannya, melalui proses konseling yang menekankan pada perubahan cara berpikir irasional menjadi rasional peserta didik memperoleh pengalaman mengembangkan mode berpikir baru yang sebagai kerangka acuan bertindak agar kosekuensi yang muncul baik emosional ataupun tingkah laku menjadi lebih baik.

\section{KESIMPULAN DAN SARAN}

\section{Kesimpulan}

1. Terdapat perubahan tingkat kecemasan peserta didik Sekolah Menengah Pertama Islam Terpadu (SMP-IT) Masjid Syuhadak Yogyakarta setelah diberikan layanan konseling kelompok menggunakan pendekatan Rational Emotive Behavior Therapy (REBT).

2. Layanan konseling kelompok menggunakan pendekatan Rational 
Emotive Behavior Therapy (REBT) yang secara empiris terbukti (REBT) terbukti efektif dapat menurunkan tingkat kecemasan menurunkan kecemasan peserta peserta didik.

didik Sekolah Menengah Pertama Islam Terpadu (SMP-IT) Masjid

\section{DAFTAR PUSTAKA}

Syuhadak Yogyakarta.

\section{Saran}

Gantina Komalasari, dkk. 2016. Teori dan Teknik Konseling. Jakarta Barat: PT Indeks

Guru BK diharapkan dapat meningkatkan upaya membantu mengatasi masalah kecemasan yang dialami peserta didik melalui pemberian layanan konseling kelompok menggunakan pendekatan Rational Emotive Behavior Therapy

Kurnanto. 2013. Konseling Kelompok. Bandung: Alfabeta

Tohirin. 2013. Bimbingan dan Konseling di Sekolah dan Madrasah (Berbasis Integritas). Jakarta: Rajawali Pers 